IOSR Journal of Pharmacy

e-ISSN: 2250-3013, p-ISSN: 2319-4219, www.iosrphr.org

Vol. 2, Issue 6, Nov-Dec. 2012, PP. 05-07

\title{
Bilateral Variation in Formation of Median Nerve
}

\author{
S. Talhar ${ }^{1}$, B. R. Sontakke ${ }^{2}$, P Bokariya ${ }^{2,}$ A.M. Tarnekar ${ }^{3}$, M. R. Shende ${ }^{4}$ \\ ${ }^{1}$ Senior Resident, ${ }^{2}$ Assistant Professors, ${ }^{3}$ Professor, ${ }^{4}$ Professor \& Head, \\ Dept of Anatomy, MGIMS, Sevagram
}

\begin{abstract}
During routine dissection of undergraduate students in the academic year 2009-2010 in department of anatomy, upper extremity of a male cadaver of about 63 years of age showed bilateral variation in the formation of median nerve. Median nerve received contribution from lateral cord twice. However; the distribution of the median nerve was normal in the arm, forearm and palm. The arterial pattern in the arm was also normal.
\end{abstract}

Keywords:- Median nerve, Variation

\section{INTRODUCTION}

The complex network of brachial plexus is formed by the incorporation of the ventral rami of the lower four cervical and first thoracic spinal nerves. The median nerve is formed by the union of two roots- lateral root of median nerve (LRM) arising from lateral cord (roots C5, C6 and C7) of brachial plexus and medial root of median nerve (MRM) arising from the medial cord (roots C8 and T1) of brachial plexus. These roots embrace the third part of axillary artery and unite anterior or lateral to it ${ }^{1}$.The variations of brachial plexus and its terminal branches are common and have been widely documented. The aim of this study was to provide additional information about variation in the formation of median nerve.

\section{CASE REPORT}

During routine undergraduate dissection of axilla of a male cadaver of about 63 years of age it was noticed that lateral cord gave a branch in additional to usual three branches. This additional branch (LRM-1) was contributed to median nerve in addition to the usual LRM (referred here as LRM-2). LRM-1 was present bilaterally and thus median nerve was formed by the contribution of three roots on both sides- two from the lateral cord (LRM-1 and LRM-2) and one from the medial cord (MRM) of brachial plexus. The beginning point of variant lateral root of median nerve (LRM-1) was proximal to the origin of musculocutaneous nerve from the lateral aspect of second part of axillary artery. LRM-1 joined the medial root of median nerve (MRM) just distal to the lateral border of pectoralis minor and much proximal to usual joining point of MRM and LRM. Both LRM-1 and LRM-2 were of equal diameter on both sides (Figure $1 \& 2$ ). The finding on left side was more or less same. The median nerve formed in this way (MN') was in front of the third part of axillary artery. Distally this median nerve (MN') received another contribution from lateral cord as LRM-2 close to the lower border of teres major muscle (lower boundary of axilla) just lateral to the axillary artery and then the definitive median nerve $(\mathrm{MN})$ coursed downwards lateral to the artery in upper part of arm. After this the further course distribution of the median nerve was as usual in the arm, forearm and hand.

\section{DISCUSSION}

Variations in the formation and branching of the brachial plexus are common and have been reported by several investigators. In the present study, the median nerve was formed by more than two roots. Several workers have reported similar findings. Chauhan and Roy reported formation of median nerve by two lateral and one medial roots $^{2}$.Similar finding was observed by Saeed and Rufai ${ }^{3}$.Satyanarayana and Guha reported formation of median nerve by four roots (three lateral and one medial root) ${ }^{4}$.The ulnar nerve has its roots C7, C8 and T1 and it is a branch of medial cord. However the medial cord is not contributed by the $\mathrm{C} 7$ root at all. To have C7 root in it the ulnar nerve must receive the contribution from lateral cord. It is a common variation of the brachial plexus to find contribution to ulnar nerve from lateral cord ${ }^{5}$.Ulnar nerve may even receive a small branch from lateral cord which is sometimes called lateral root of ulnar nerve ${ }^{5}$. In present case it is quite likely that LRM-1 might contribute $\mathrm{C} 7$ root to ulnar nerve in addition to the usual contribution to median nerve. Such variations can also be explained in the light of embryonic development. The first indication of limb musculature is observed in the seventh week of development as condensation of mesenchyme near the base of limb buds. With further elongation of limb buds, the muscle tissue splits into flexor and extensor compartments. The upper limb buds lie opposite the lower five cervical and upper two thoracic segments. As soon as the buds form, ventral primary rami from the spinal nerves penetrate into the mesenchyme. These rami divide into ventral and dorsal 
divisions to supply flexor and extensor group of muscles respectively. Immediately after the above mentioned rearrangements of nerves, theyenter the limb buds and establish an intimate contact with the differentiating mesodermal condensation and this early contact between the nerve and muscle cell is a prerequisite for their complete functional differentiation. The ventral rami form the roots of the limb plexus. The named peripheral nerves thus have different contributions from one or several such roots as they are formed by complex branching and reunion of these. Such complex biological phenomena are likely to invite variations. This knowledge about variation in median nerve is important to surgeons, clinicians during routine surgery of axilla and upper arm.

\section{REFERENCES}

1) David J,Harold E. Gray's anatomy. In: Pectoral girdle, shoulder region and axilla.40th ed. New York Churchill Livingstone Elsevier, 2008; 791-822.

2) Chauhan, Roy Communication between the median and musculocutaneous nerve- a case report, Journal of the anatomical society of India.2002: 52(1): 72-5.

3) Saeed R- Median nerve and musculocutaneous nerves: variant formation and distribution. Clinical Anatomy.2003: 16: 453-7.

4) Satyanarayana N, Guha R- Formation of median nerve by four roots. J college of medical sciences 2008; 5(1): 105-7.

5) Hollingshead WH Anatomy for surgeons .In: General Survey of the Upper Limb.2nd ed.New York Harper and Row, 1969 .Vol (3); 236-40.

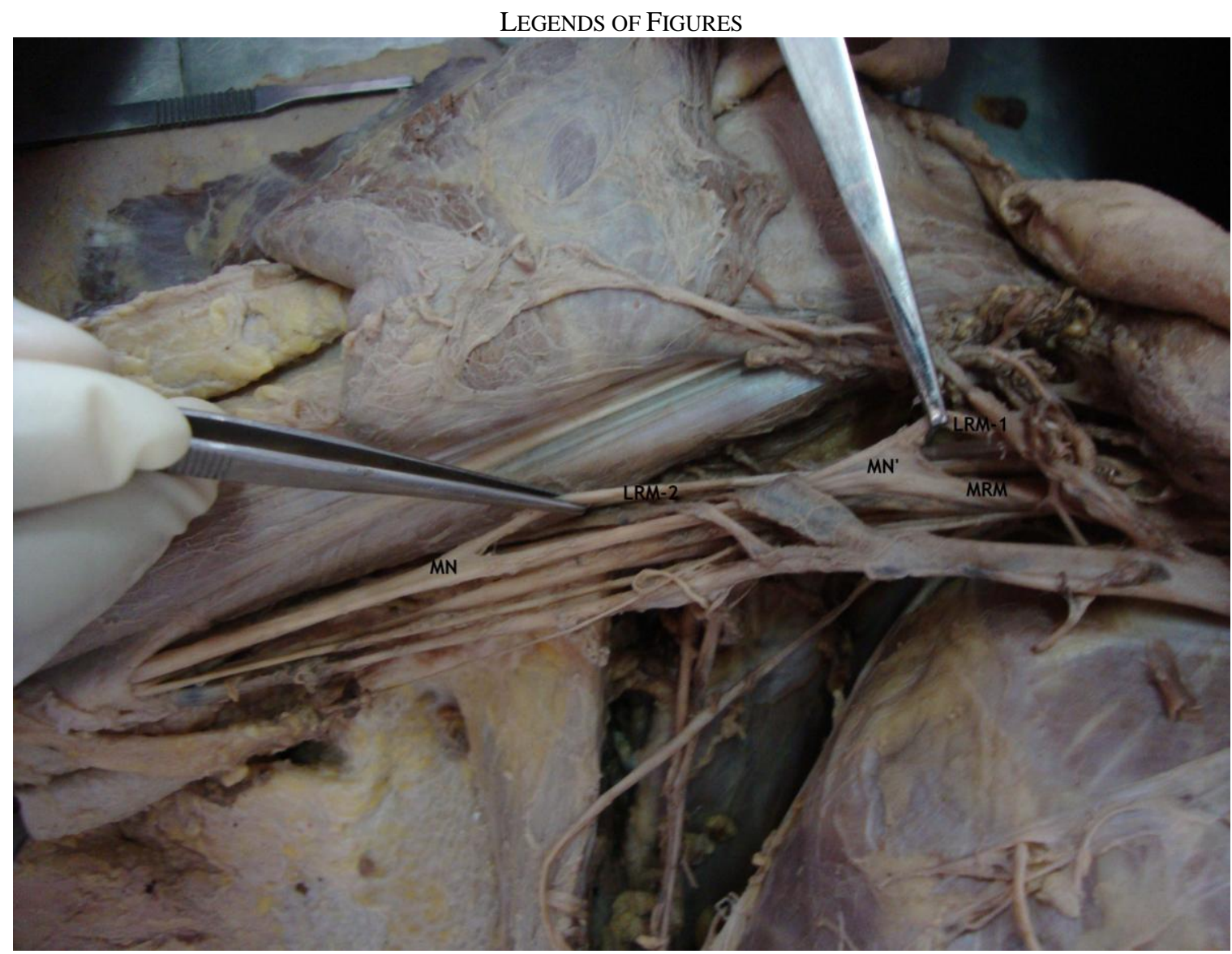

Figure 1: Showing abnormal formation of median nerve on Right side. LRM-1: variant lateral root of median nerve, LRM-2 : usual lateral root of median nerve,MRM: Medial root of median nerve, MN':Median nerve formed by union of LRM-1 and MRM, MN: Definitive median nerve. 


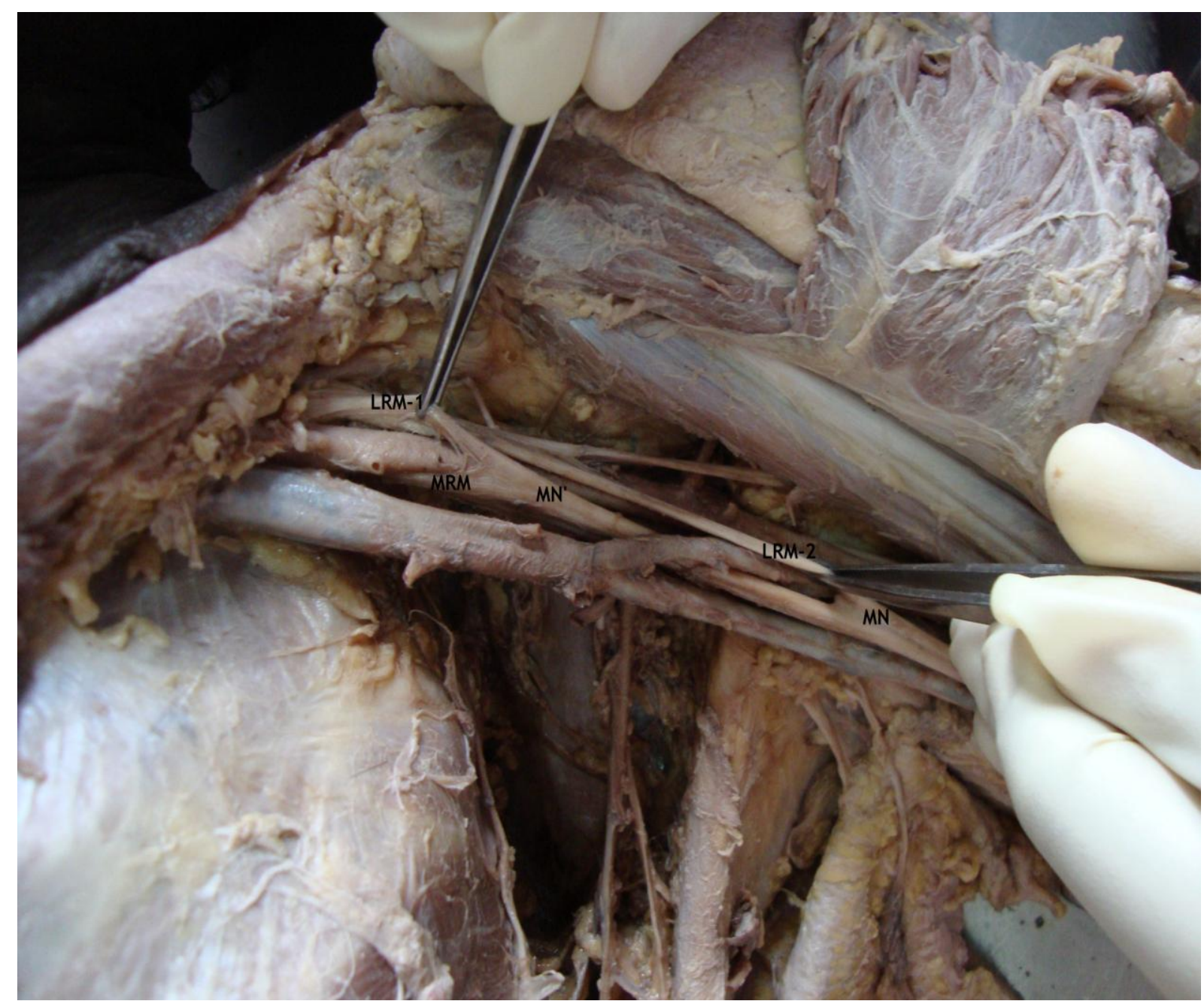

Figure 2: Showing abnormal formation of median nerve on left side. LRM-1: variant lateral root of median nerve, LRM-2 : usual lateral root of median nerve,MRM: Medial root of median nerve, MN':Median nerve formed by union of LRM-1 and MRM, MN: Definitive median nerve. 